\title{
The epidemiology of herpes zoster and its complications in Medicare cancer patients
}

\author{
Mihran A Yenikomshian ${ }^{*}$, Adrienne P Guignard ${ }^{2}$, François Haguinet ${ }^{2}$, Ann S LaCasce ${ }^{3}$, Arthur T Skarin ${ }^{3}$, \\ Alex Trahey ${ }^{1}$, Paul Karner ${ }^{1}$ and Mei Sheng Duh ${ }^{1}$
}

\begin{abstract}
Background: Literature on the epidemiology of herpes zoster $(\mathrm{HZ})$ in cancer patients is sparse and does not include the elderly. The objectives of this study were to determine the incidence of $\mathrm{HZ}$ and related complications in elderly cancer patients and assess risk factors associated with $\mathrm{HZ}$.

Methods: Patients $\geq 65$ years diagnosed with cancer in 1991-2007 were identified from the Surveillance, Epidemiology, and End Results (SEER) cancer registry-Medicare linked database in this retrospective, longitudinal, open cohort study. The observation period spanned from first cancer diagnosis until the end of data availability. A random group of non-cancer Medicare patients served as the comparison group. Cases of $\mathrm{HZ}$ and related complications were ascertained from medical claims. Incidence rates (IR) and adjusted IR ratios were reported.

Results: The study population consisted of 82,832 hematologic (HEM) and 944,777 solid cancer patients (SOLID). During follow-up, $9.2 \%$ of HEM and $6.3 \%$ of SOLID were diagnosed with HZ. The IR of HZ was significantly higher in HEM than SOLID (31.0 vs. 14.9 per 1,000 patient-years, $\mathrm{p}<0.01$ ). The adjusted IR ratio vs. non-cancer elderly patients was 2.4 in HEM and 1.2 in SOLID. The proportion of patients with complications was higher in HEM than SOLID (17.8\% vs. 15.8\%, $p<0.01)$. Age, gender, race, certain cancer therapies, and immunosuppression were $\mathrm{HZ}$ risk factors.
\end{abstract}

Conclusions: Elderly cancer patients run a 1.2-2.4 times higher risk of developing $\mathrm{HZ}$ than those without cancer. The rates of $\mathrm{HZ}$ and $\mathrm{HZ}$-related complications are significantly higher for hematologic than solid cancer patients.

Keywords: herpes zoster, Neoplasms, Incidence, Elderly, Risk factors, Neuralgia, Postherpetic neuralgia

\section{Background}

herpes zoster $(\mathrm{HZ})$ is a vesicular rash associated with acute pain, caused by the varicella zoster virus (VZV) [1]. An estimated 1 million cases of $\mathrm{HZ}$ are reported annually in the US alone [2]. The risk of HZ increases when VZV-specific cell-mediated immunity declines, as a result of older age and/or immunosuppressive medical conditions and treatments $[3,4]$.

There is sparse knowledge about the epidemiology of $\mathrm{HZ}$ in cancer patients, particularly among the elderly. Estimates from existing literature indicate the incidence of $\mathrm{HZ}$ is 2-4 times higher in cancer patients compared to the general population. The most recent literature on $\mathrm{HZ}$ in cancer patients covers commercially-insured patients

\footnotetext{
* Correspondence: Mihran.Yenikomshian@analysisgroup.com

'Analysis Group, Inc., 111 Huntington Ave., Tenth Floor, Boston, MA 02199, USA

Full list of author information is available at the end of the article
}

diagnosed with cancer during 2001-2005 [5,6]. This study contributes to the body of literature by analyzing patients diagnosed with cancer during 1991-2007 and in the Medicare population.

The objectives of this study were to estimate the incidence of HZ, HZ-related pain, and HZ complications in elderly patients with selected hematologic and solid cancers, and to investigate risk factors for developing HZ in this population. Cancers were selected based on their prevalence as well as their known elevated risk of $\mathrm{HZ}$.

\section{Methods \\ Data source}

This study utilized the Surveillance, Epidemiology, and End Results (SEER)-Medicare database, derived from a link between two large population-based data sources: the SEER cancer registries data, which cover approximately $28 \%$ of the US population [7] and contain 
information on cancer diagnoses, tumors, and mortality; and the Medicare enrollment and claims files, which cover the majority of US population aged $\geq 65$ and contain charges and reimbursements for hospital, outpatient, physician, and home health claims. The link between the two databases was created by the US National Cancer Institute and the Centers for Medicare and Medicaid Services by matching individual identifiers from registries participating in the SEER program with identifiers contained in Medicare's master enrollment file. The linked SEER-Medicare data include the records of approximately $93 \%$ of SEER cancer patients aged $\geq 65$ [8]. The number of cancer registries covered by the SEER program has expanded over time, including during the period covered by our study.

The SEER program collects information about primary cancers such as cancer site, stage, histology, and first course of treatment for persons newly diagnosed with cancer who reside in one of the SEER geographic areas. The Medicare master enrollment file was used to determine which persons in the SEER data are Medicare beneficiaries. For people who are Medicare eligible, the SEER-Medicare data include claims for covered healthcare services, including hospital, physician, outpatient, home health, and hospice bills.

The analyses are based on Medicare claims during 19912009 of patients diagnosed with cancer during 1991-2007. The claims data include Medicare Part D pharmacy claims during 2007-2009. In addition, a cohort of non-cancer patients comprised of a random $5 \%$ sample of Medicare beneficiaries residing in the SEER registry areas is contained in the SEER-Medicare data and was included in our study for comparison. The New England Institutional Review Board approved this retrospective analysis of SEER-Medicare data as exempt from review due to the research involving the study of existing data (informed consent was waived).

\section{Study design}

This was a retrospective, longitudinal, open cohort study. From the set of all Medicare-eligible patients in the SEER registry who were diagnosed with cancer from 1991-2007, those who were $\geq 65$ years old at the time of cancer diagnosis, had $\geq 6$ months of continuous insurance eligibility prior to cancer diagnosis, were covered by both Part A and Part B Medicare without Health Maintenance Organization enrollment, and had no evidence of cancer therapy or HZ diagnosis prior to cancer diagnosis were included in the main sample. Patients in the non-cancer comparison cohort were selected based on the same criteria.

The index date for cancer patients was defined as the date of cancer diagnosis. For the non-cancer cohort, an index date was needed in order to facilitate comparisons with the cancer cohorts. This index date for non-cancer patients was randomly assigned such that, following assignment, the mean and standard deviation of Medicare eligibility prior to the index date were the same as those for cancer patients. The observation period ran from the index date to the earlier of the end of data availability (December 31, 2009) or death.

\section{Definitions}

An incident $\mathrm{HZ}$ case was defined as the first claim for an HZ episode (ICD-9 codes 053.X except 053.12 and 053.13) [9]. Both generalized and localized HZ cases were included. HZ-associated cutaneous, visceral, neurological, and ocular complications were identified by ICD-9 codes on claims within 90 days after any $\mathrm{HZ}$ claim in cases for which there was no claim for the complication prior to the date of first $\mathrm{HZ}$ diagnosis $[2,10,11]$. Given the time period and availability of data, the following criteria for HZ-related pain applied to the vast majority of patients: (i) two or more visits with an $\mathrm{HZ}$ diagnosis more than 28 days apart; or (ii) a diagnosis for $\mathrm{HZ}$ with other nervous system complications (ICD-9CM 053.1x) or a diagnosis for neuralgia (ICD-9-CM 729.2) within 180 days of a visit for $\mathrm{HZ}$. With the availability of Medicare Part D data beginning in 2007, a new prescription for a medication used to treat HZ-related pain was also required within 60 days of the $\mathrm{HZ}$ visits in the first criterion. A similar definition was adopted by Klompas, et al. to address the under-coding of post-herpetic neuralgia [12]. This definition accounts for the possibility that pain is underreported in the claims data by allowing for HZ-related pain without a pain claim (see Additional file 1: Table S1 for codes used to identify pain and pain interventions). We include in our estimates of the percentage of patients instances in which claims for HZ-related complications (see Additional file 1: Table S2 for the codes used to identify HZ-related complications) occur on the same claim as the initial HZ diagnosis since this is a relatively frequent occurrence in the data. In these instances, we cannot be certain that what we are observing are incident complications. Hence, the estimates of the percentage of patients developing each complication can be characterized as the prevalence of the complication within the 90-day period following $\mathrm{HZ}$ diagnosis.

\section{Statistical analysis}

Demographic characteristics, observation time pre- and post-index date, and the Charlson Comorbidity Index (see Additional file 1: Table S3 for the description of the Charlson Comorbidity Index) [13-15] were reported. Cancer patients were stratified by cancer site and into cohorts based on cancer type (hematologic and solid). Frequencies and proportions (means and standard deviations) were reported for categorical variables (continuous variables). Differences between any cancer and non-cancer, hematologic and non-cancer, and solid and non-cancer 
patients were tested using chi-squared and t-tests for categorical and continuous variables, respectively.

The HZ incidence rate (IR) was estimated as the number of patients with incident $\mathrm{HZ}$ divided by person-years (PY) of observation censored at the earlier of first event or death. Confidence intervals $(\mathrm{CI})$ were estimated using the exact Poisson confidence limit. Results were stratified by cancer site. A z-test was used to assess the difference between IRs of $\mathrm{HZ}$ for hematologic vs. solid cancers.

Adjusted incidence rate ratios (IRR) of $\mathrm{HZ}$ in cancer vs. non-cancer patients and 95\% CIs were estimated by Poisson regressions using the covariates age at diagnosis, gender, HIV-positive, diabetic, race, and immunocompromising conditions/medications (e.g., rheumatoid arthritis, lupus erythematosus, medications inhibiting tumor necrosis factor - see Additional file 1: Table S3 for description of immunocompromising conditions/ medications) to assess the incremental risk of $\mathrm{HZ}$ for cancer vs. non-cancer patients. Separate regressions were run on the samples of hematologic and solid cancer patients. Risk factors for developing $\mathrm{HZ}$ were assessed with IRRs estimated from Poisson regressions with the same set of covariates listed above as well as receipt of certain cancer therapies (hematologic cancer patients: autologous and allogeneic stem cell transplants; solid cancer patients: radiotherapy) and cancer stage at diagnosis (solid cancer patients only). Covariates whose estimated IRRs differed significantly from 1.0 were deemed to be risk factors for $\mathrm{HZ}$. The proportions of patients with $\mathrm{HZ}$ at different time points during follow-up were also calculated. Receipt of chemotherapy, which was expected to be highly correlated with receipt of antiviral prophylaxis, could not be assessed as an independent $\mathrm{HZ}$ risk factor due to the lack of available pharmacy claims data prior to 2007.

Frequencies of events, observation time, proportions of $\mathrm{HZ}$ patients, and IRs for HZ-related complications were reported separately for the hematologic and solid cohorts. Events, observation time, and proportion of patients were based on complications diagnosed within 90 days of $\mathrm{HZ}$ diagnosis, and should thus be interpreted as the 90 day prevalence of complications. The IRs for HZ-related complications were calculated by Poisson regression with a log link. Patients with complications diagnosed on the same day as $\mathrm{HZ}$ are excluded from the regression due to lack of follow-up time. Reported estimates of 95\% CIs for the IRs were estimated using the exact Poisson confidence limit. Frequencies of events and proportions of patients with HZ-related pain were reported by cancer site. Z-tests were used to assess the difference between the proportions of hematologic and solid cancer patients who developed HZrelated complications and pain.

All data analyses were performed using SAS release 9.2 or newer (SAS Institute, Inc., Cary, NC).

\section{Results}

\section{Sample characteristics}

From an initial sample of 2,110,735 cancer and 676,712 non-cancer patients, the final sample included 82,832 hematologic, 944,777 solid, and 246,308 non-cancer patients (see Figure 1). Patient baseline characteristics are presented in Table 1. Significant differences existed between cancer and non-cancer patients in all characteristics considered. Due to the large sample size, not all statistically significant differences were meaningful. The average age at the index date was approximately 75-78 years across the cohorts. Compared with non-cancer patients, hematologic and solid cancer patients were slightly older on average (mean ages 77.5 and 76.1 vs. 74.7 years, p-values <0.0001). Most $(62.7 \%)$ non-cancer patients were female, while hematologic cancer patients were roughly evenly divided across genders $(51.0 \% \mathrm{fe}-$ male) and solid cancer patients tended to be male (55.1\%). Most (84-89\%) patients were White in race. Compared with non-cancer patients, larger proportions of hematologic and solid cancer patients were White (89.3\% and $86.4 \%$, respectively, vs. $84.1 \%$ ), while smaller proportions were Asian/Pacific Islanders (2.2-2.3\% vs. $3.2 \%)$ and North American Native/Alaska Native $(0.2 \%$ vs. $0.4 \%)$. A smaller proportion of hematologic cancer patients were Black (4.7\%) compared with solid cancer (7.9\%) and non-cancer (7.6\%) patients. Average followup times for hematologic and solid cancer patients were 37.8 and 52.1 months, respectively, and were significantly shorter compared to non-cancer patients (mean 85.3 months, $\mathrm{p}$-values $<0.0001)$.

\section{Incidence rates of herpes zoster}

Results on the IR of HZ are presented in Table 2. Across the cancer types considered, the IR of HZ was lowest for patients with prostate cancer and highest for patients with Hodgkin's Lymphoma (12.3 and 47.8 per 1,000 PY, respectively). The IR of $\mathrm{HZ}$ was significantly higher in the hematologic vs. solid cancer cohort (31.0 vs. 14.9 per $1,000$ PY, $\mathrm{p}<0.01)$. Both hematologic and solid cancer patients were more likely to develop $\mathrm{HZ}$ compared to non-cancer patients (adjusted IRRs of 2.36 and 1.19, pvalues $<0.001)$.

The proportions of patients developing $\mathrm{HZ}$ by time since index date are plotted in Figure 2 (cancer patients in this analysis were required to have survived for at least 2 years after cancer diagnosis). Approximately 3.75\% and $1.50 \%$ of patients in the hematologic and solid cancer cohorts developed $\mathrm{HZ}$ within 1 year of cancer diagnosis, compared with $1.10 \%$ of non-cancer patients. The proportions of hematologic and solid cancer patients who developed $\mathrm{HZ}$ within 2 years of cancer diagnosis were $6.6 \%$ and $3.0 \%$, respectively. Overall, $9.2 \%$ of hematologic and $6.3 \%$ of solid cancer patients were diagnosed with $\mathrm{HZ}$ during 


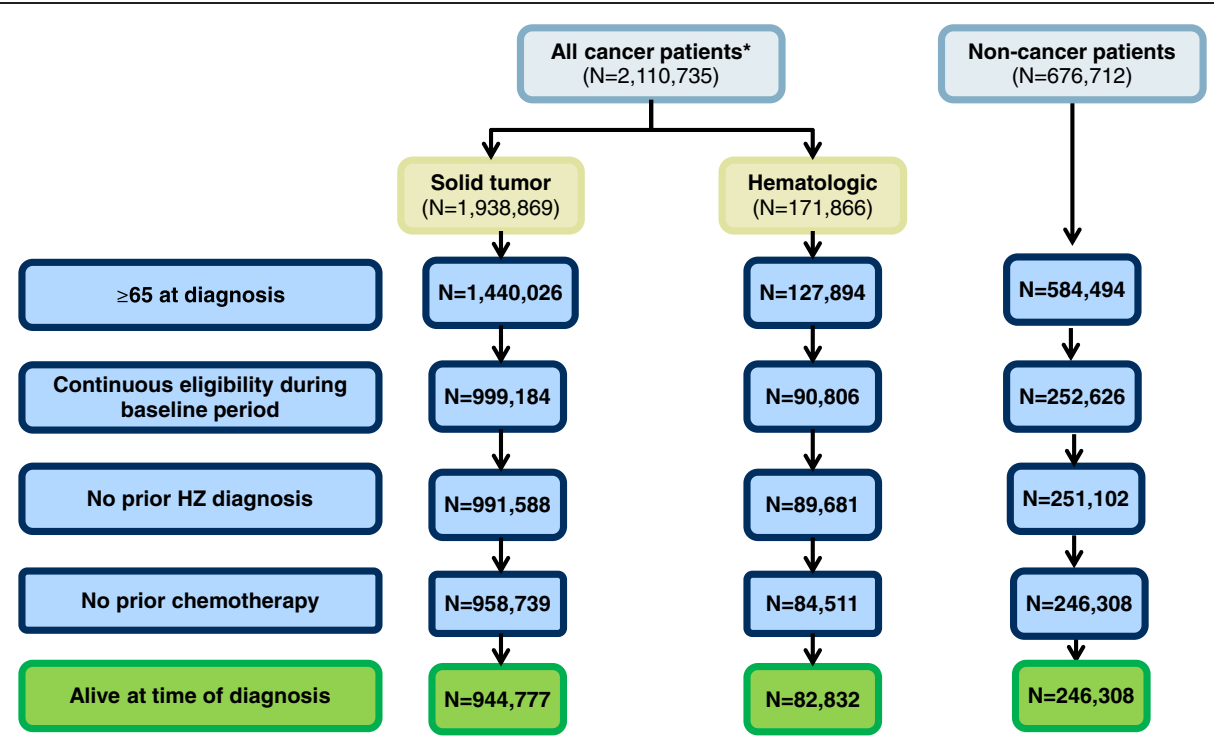

Note:

* Denotes first cancer diagnosis only

Figure 1 Study population disposition. The flow chart depicts how the selection criteria affect the number of patients remaining in the study sample. Each box represents the number of patients remaining in the sample at each step. From an initial sample of 2,110,735 cancer and 676,712 non-cancer patients, the final sample included 82,832 hematologic, 944,777 solid, and 246,308 non-cancer patients.

follow-up. Among patients who developed HZ, the median time of $\mathrm{HZ}$ onset following cancer diagnosis was 34.0 months (24.8 and 35.4 months for hematologic and solid tumor patients, respectively).

\section{herpes zoster risk factors}

Results from the analysis of risk factor for $\mathrm{HZ}$ are presented in Table 3. Age, gender, race, and immunocompromising conditions and/or medications were statistically significant risk factors for $\mathrm{HZ}$. Conditional on cancer status, estimates from the sample that included hematologic cancer patients indicate that patients 75 to 85 years old ran a higher risk of developing $\mathrm{HZ}$ compared with patients $\geq 85$ years $(\operatorname{IRR}=1.12, \mathrm{p}<0.001)$. Males were at lower risk of developing $\mathrm{HZ}$ than females (IRR $=0.83, \mathrm{p}<0.001$ ). Black patients were less likely to develop $\mathrm{HZ}$ than white patients $(I R R=0.64, \mathrm{p}<0.001)$. Patients who had immunocompromising conditions other than HIV ran a higher risk of developing $\mathrm{HZ}(\mathrm{IRR}=1.25, \mathrm{p}<0.001)$. Finally, receipt of autologous or allogeneic stem cell transplants was associated with a higher risk of developing HZ (IRRs of 2.07, $\mathrm{p}<0.001$; and 1.92, $\mathrm{p}=0.024$, respectively). Results from the sample that included solid cancer patients were largely similar. Radiotherapy recipients ran a slightly lower risk of developing $\mathrm{HZ}$ compared to solid cancer patients who did not receive radiotherapy (IRR $=0.94, \mathrm{p}<0.001$ ) while patients with stage III/IV cancer at diagnosis ran a higher risk of developing HZ (IRR = 1.20, p < 0.001).

\section{herpes zoster-related complications and pain}

Results on the incidence of HZ-related complications in hematologic and solid cancer patients are presented in Table 4. Among hematologic cancer patients, the range of IRs across the different types of complications considered was wide ( 0.0 for deafness, other neurological complications, and panopthalmitis to 132.5 for postherpetic polyneuropathy and postherpetic trigeminal neuralgia). $17.8 \%$ of hematologic cancer patients developed some type of complication (IR $=530.0$ per $1,000 \mathrm{PY}$ ). Ophthalmic complications were the most prevalent $(11.3 \%$ of patients; IR $=247.3$ per 1,000 PY) compared with the other types of complications considered aside from HZ-related pain. Similar proportions of hematologic and solid cancer patients developed HZrelated complications across the major categories of complications considered, although a significantly larger share of hematologic cancer patients developed complications ( $17.8 \%$ vs. $15.8 \%$ of patients, $\mathrm{p}<0.01$ ).

Results on the incidence of HZ-related pain are presented in Table 5. The proportions of hematologic and solid cancer patients who developed HZ-related pain were $47.7 \%$ and $41.0 \%$, respectively. Significantly higher proportions of hematologic cancer patients developed HZ-related pain compared to solid cancer patients (p-values $<0.01$ ).

\section{Discussion}

This study of elderly patients was undertaken to describe the characteristics of patients with and without cancer, 
Table 1 Patient baseline characteristics

\begin{tabular}{|c|c|c|c|c|c|}
\hline & $\begin{array}{l}\text { Hematologic cancer } \\
\text { patients }^{1}\end{array}$ & $\begin{array}{l}\text { Solid cancer } \\
\text { patients }^{2}\end{array}$ & $\begin{array}{l}\text { Non-cancer } \\
\text { patients }\end{array}$ & $\begin{array}{l}\text { P-value hematologic } \\
\text { cancer vs. non-cancer }\end{array}$ & $\begin{array}{l}\text { P-value solid cancer } \\
\text { vs. non-cancer }\end{array}$ \\
\hline Age at index date, mean $\pm S D^{3}$ & $77.5 \pm 7.3$ & $76.1 \pm 6.9$ & $74.7 \pm 7.2$ & $<0.0001$ & $<0.0001$ \\
\hline \multicolumn{6}{|l|}{ Gender, n (\%) } \\
\hline Male & $40,516(49.0 \%)$ & $516,011(55.1 \%)$ & $91,940(37.3 \%)$ & $<0.0001$ & $<0.0001$ \\
\hline Female & $42,232(51.0 \%)$ & $419,916(44.9 \%)$ & $154,368(62.7 \%)$ & $<0.0001$ & $<0.0001$ \\
\hline \multicolumn{6}{|l|}{ Race, n (\%) } \\
\hline White & $73,895(89.3 \%)$ & $808,178(86.4 \%)$ & $207,161(84.1 \%)$ & $<0.0001$ & $<0.0001$ \\
\hline Black & $3,923(4.7 \%)$ & $74,168(7.9 \%)$ & $18,760(7.6 \%)$ & $<0.0001$ & $<0.0001$ \\
\hline Asian/Pacific Islander & $1,800(2.2 \%)$ & $21,116(2.3 \%)$ & $7,811(3.2 \%)$ & $<0.0001$ & $<0.0001$ \\
\hline Hispanic & $1,203(1.5 \%)$ & $12,237(1.3 \%)$ & $5,896(2.4 \%)$ & $<0.0001$ & $<0.0001$ \\
\hline North American Native/Alaska Native & $155(0.2 \%)$ & $1,952(0.2 \%)$ & $901(0.4 \%)$ & $<0.0001$ & $<0.0001$ \\
\hline Other & $1,489(1.8 \%)$ & $15,674(1.7 \%)$ & $5,013(2.0 \%)$ & $<0.0001$ & $<0.0001$ \\
\hline Months before the index date, mean $\pm S D^{3}$ & $110.9 \pm 64.8$ & $101.4 \pm 62.4$ & $85.6 \pm 47.6$ & $<0.0001$ & $<0.0001$ \\
\hline Months after the index date, mean $\pm S D^{3}$ & $37.8 \pm 41.3$ & $52.1 \pm 48.8$ & $85.3 \pm 62.6$ & $<0.0001$ & $<0.0001$ \\
\hline Charlson Comorbidity Index, mean $\pm \mathrm{SD}^{3}$ & $0.7 \pm 1.1$ & $0.7 \pm 1.1$ & $0.5 \pm 0.9$ & $<0.0001$ & $<0.0001$ \\
\hline
\end{tabular}

Notes:

${ }^{1}$ Hematologic cancers include chronic lymphocytic leukemia, acute lymphocytic or acute myeloid leukemia, other leukemia, Hodgkin's lymphoma, and non-Hodgkin's lymphoma.

${ }^{2}$ Solid cancers include bladder cancer, breast cancer, colorectal cancer, head and neck cancer, lung cancer, melanoma, ovarian cancer, prostate cancer, and soft tissue sarcoma.

${ }^{3} \mathrm{SD}=$ standard deviation

Table 2 Incidence of herpes zoster in cancer patients

\begin{tabular}{|c|c|c|c|c|c|c|}
\hline & Patients & $\begin{array}{l}\text { First } \\
\text { events }\end{array}$ & $\begin{array}{l}\text { Person-years } \\
\text { of observation }\end{array}$ & $\begin{array}{l}\text { IR Per } 1,000 \\
\text { person-years }(95 \% \mathrm{CI})^{1}\end{array}$ & $\begin{array}{l}\text { Adjusted IRR vs. } \\
\text { non-cancer patients }(95 \% \mathrm{Cl})^{1}\end{array}$ & P-value \\
\hline All Cancers & $1,027,609$ & 66,222 & $4,161,133$ & $15.9(15.8-16.0)$ & $1.27(1.25-1.29)$ & $<0.001$ \\
\hline Hematologic Cancers ${ }^{2}$ & 82,832 & 7,574 & 244,187 & $31.0(30.3-31.7)$ & $2.36(2.30-2.42)$ & $<0.001$ \\
\hline Chronic Lymphocytic Leukemia & 14,035 & 1,754 & 56,875 & $30.8(29.4-32.3)$ & $2.37(2.26-2.49)$ & $<0.001$ \\
\hline $\begin{array}{l}\text { Acute Lymphocytic or Acute } \\
\text { Myeloid Leukemia }\end{array}$ & 9,614 & 257 & 7,125 & $35.9(31.8-40.6)$ & $2.75(2.43-3.11)$ & $<0.001$ \\
\hline Other Leukemia & 7,803 & 391 & 15,685 & $24.9(22.5-27.5)$ & $1.90(1.72-2.11)$ & $<0.001$ \\
\hline Hodgkin's Lymphoma & 2,147 & 283 & 5,923 & $47.8(42.5-53.7)$ & $3.56(3.17-4.01)$ & $<0.001$ \\
\hline Non-Hodgkin's Lymphoma & 49,233 & 4,891 & 158,773 & $30.7(29.9-31.6)$ & $2.31(2.24-2.39)$ & $<0.001$ \\
\hline Solid Cancers $^{2}$ & 944,777 & 58,670 & $3,921,307$ & $14.9(14.8-15.1)$ & $1.19(1.17-1.21)$ & $<0.001$ \\
\hline Bladder Cancer & 67,811 & 4,140 & 293,432 & $14.1(13.7-14.5)$ & $1.11(1.08-1.16)$ & $<0.001$ \\
\hline Breast Cancer & 173,635 & 15,819 & 963,395 & $16.4(16.2-16.7)$ & $1.17(1.14-1.19)$ & $<0.001$ \\
\hline Colorectal Cancer & 129,761 & 7,354 & 504,238 & $14.6(14.2-14.9)$ & $1.11(1.08-1.14)$ & $<0.001$ \\
\hline Head and Neck Cancer & 48,876 & 2,530 & 173,559 & $14.6(14.0-15.2)$ & $1.14(1.09-1.19)$ & $<0.001$ \\
\hline Lung Cancer & 200,734 & 6,376 & 287,656 & $22.1(21.6-22.7)$ & $1.61(1.56-1.66)$ & $<0.001$ \\
\hline Melanoma & 52,026 & 3,961 & 268,256 & $14.8(14.3-15.2)$ & $1.15(1.11-1.19)$ & $<0.001$ \\
\hline Ovarian Cancer & 18,715 & 844 & 48,762 & $17.3(16.2-18.5)$ & $1.21(1.13-1.30)$ & $<0.001$ \\
\hline Prostate Cancer & 247,939 & 17,371 & $1,406,361$ & $12.3(12.2-12.5)$ & $1.12(1.09-1.15)$ & $<0.001$ \\
\hline Soft Tissue Sarcoma & 5,280 & 275 & 18,206 & $15.1(13.4-16.9)$ & $1.16(1.03-1.31)$ & 0.016 \\
\hline
\end{tabular}

${ }^{1} \mathrm{IR}=$ incidence rate; $\mathrm{IRR}=\mathrm{IR}$ ratio; $\mathrm{Cl}=$ confidence interval.

${ }^{2} \mathrm{P}$-value of difference in IR of $\mathrm{HZ}$ for hematologic vs. solid cancer $<0.01$. 


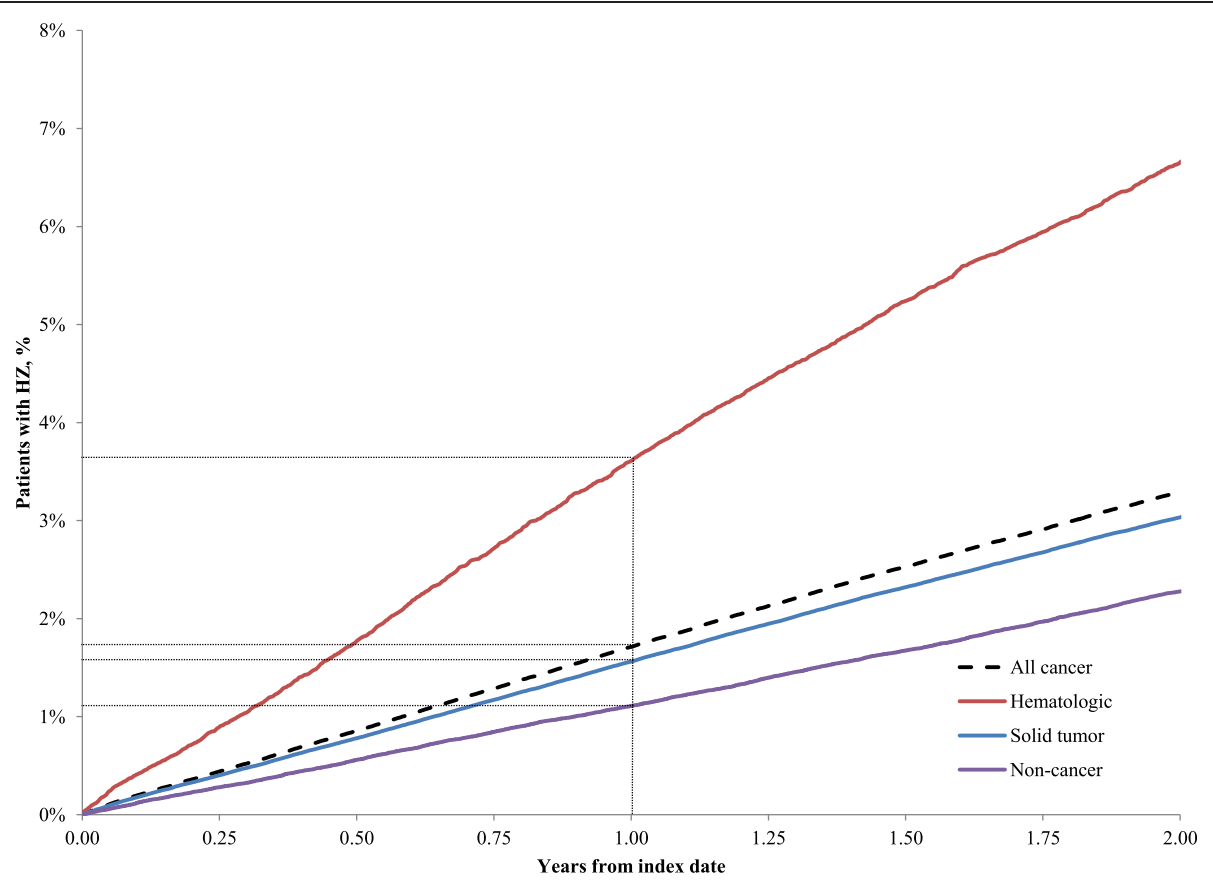

Figure 2 Proportions of patients developing herpes zoster after cancer diagnosis. The proportions of patients developing $\mathrm{HZ}$ by time since index date are plotted. Cancer patients in this analysis were required to have survived for at least 2 years after cancer diagnosis. The proportion of patients being diagnosed with $\mathrm{HZ}$ was plotted for the overall, hematologic, solid tumor, and non-cancer cohorts. Dashed lines indicate the percentage of each cohort with $\mathrm{HZ}$ at 1 year since the index date. Approximately $3.75 \%$ and $1.50 \%$ of patients in the hematologic and solid cancer cohorts developed $\mathrm{HZ}$ within 1 year of cancer diagnosis, compared with $1.10 \%$ of non-cancer patients. The proportions of hematologic and solid cancer patients who developed $\mathrm{HZ}$ within 2 years of cancer diagnosis were $6.6 \%$ and $3.0 \%$, respectively.

provide a comprehensive analysis of the incidence and onset of HZ, HZ-related pain, and HZ complications in elderly cancer patients, and assess risk factors for developing HZ. The SEER-Medicare database facilitated the use of large samples of cancer patients, as well as a sample of non-cancer patients for comparison purposes.

This study found significantly higher HZ incidence rates in cancer vs. non-cancer patients. Specifically, elderly cancer patients ran a 1.2-2.4 times higher risk of developing $\mathrm{HZ}$ than those without cancer. Incidence rates of $\mathrm{HZ}$ were lowest among patients with prostate cancer and highest among patients with Hodgkin's Lymphoma. Hematologic cancer patients tended to have the highest $\mathrm{HZ}$ incidence rates and develop HZ more quickly following cancer diagnosis. These findings are consistent with the previous findings of Habel, et al. and Rusthoven, et al. $[6,16]$. In particular, the $\mathrm{HZ}$ incidence rates reported by Habel, et al. in a study of a commerciallyinsured cancer population (31 and 12 per 1,000 PY for hematologic and solid cancer patients, respectively) are very similar to those found here [6]. In addition, the proportions of hematologic and solid cancer patients developing $\mathrm{HZ}$ within 2 years of cancer diagnosis found in this study (6.6\% and $3.0 \%$, respectively) are comparable to those reported by Habel et al. (6\% and 2\%, respectively). Hematologic cancer patients also developed
HZ-related complications and pain more frequently than solid cancer patients. The proportion of hematologic cancer patients with HZ developing neurologic complications (4.5\%) was comparable to, and developing cutaneous and ophthalmic complications differed from, those reported elsewhere in the literature [6,17]. In particular, the proportion of hematologic cancer patients with $\mathrm{HZ}$ that developed ophthalmic complications found in this study $(11.3 \%)$ is substantially larger than that reported by Habel et al. (3.6\%), as well as that reported by Yawn et al. in a study of $\mathrm{HZ}$ in non-cancer patients in Olmsted County, MN based on medical record review (4.1\%) [6,17].

Risk factors for developing HZ included age, gender, race, immunosuppressive conditions, and certain cancer therapies. Males and black patients (relative to white patients) had a lower risk for developing HZ, consistent with data reported by Opstelten et al. [18] (gender risk factors) and Schmader et al. [19,20] (race risk factors). Hematologic or solid cancer patients with immunocompromising conditions ran a higher risk of developing $\mathrm{HZ}$, as did hematologic cancer patients who received stem cell transplants (despite the routine use of $\mathrm{HZ}$ prophylaxis posttransplant). Additionally, solid cancer patients with a stage III/IV cancer were at a higher risk for developing HZ. Cancer patients aged 75 to 85 years old had a higher risk of developing HZ than patients 85 years and older. This 
Table 3 Risk factors for herpes zoster

\begin{tabular}{|c|c|c|c|c|c|c|}
\hline \multirow[t]{3}{*}{ Variable } & \multicolumn{3}{|c|}{ Hematologic cancers } & \multirow{2}{*}{\multicolumn{3}{|c|}{$\begin{array}{l}\text { Solid cancers } \\
(n=944,777)\end{array}$}} \\
\hline & \multicolumn{3}{|c|}{$(n=82,832)$} & & & \\
\hline & $\begin{array}{l}\text { Incidence rate } \\
\text { ratio }\end{array}$ & $95 \% \mathrm{Cl}^{1}$ & P-value & $\begin{array}{l}\text { Incidence rate } \\
\text { ratio }\end{array}$ & $95 \% \mathrm{Cl}^{1}$ & P-value \\
\hline \multicolumn{7}{|l|}{ Age at diagnosis (ref $=85+$ years old $)$} \\
\hline 65 to 75 years old & 1.05 & $(1.00-1.10)$ & 0.067 & 0.97 & $(0.94-1.00)$ & 0.025 \\
\hline 75 to 85 years old & 1.12 & $(1.07-1.18)$ & $<0.001$ & 1.04 & $(1.01-1.07)$ & 0.014 \\
\hline Male (ref = female) & 0.83 & $(0.81-0.85)$ & $<0.001$ & 0.80 & $(0.78-0.81)$ & $<0.001$ \\
\hline \multicolumn{7}{|l|}{ Race (ref = white) } \\
\hline Black & 0.64 & $(0.50-0.81)$ & $<0.001$ & 0.60 & $(0.51-0.70)$ & $<0.001$ \\
\hline Asian/Pacific Islander & 1.25 & $(0.98-1.60)$ & 0.074 & 1.28 & $(1.08-1.51)$ & 0.003 \\
\hline North American Native/Alaska Native & 1.06 & $(0.77-1.46)$ & 0.730 & 0.92 & $(0.74-1.16)$ & 0.488 \\
\hline Other or Unknown & 1.11 & $(0.87-1.43)$ & 0.398 & 1.16 & $(0.98-1.37)$ & 0.089 \\
\hline Diabetes & 1.02 & $(0.98-1.07)$ & 0.344 & 0.99 & $(0.96-1.01)$ & 0.225 \\
\hline HIV-positive (ref = HIV-negative) & 0.82 & $(0.41-1.65)$ & 0.587 & 1.16 & $(0.78-1.72)$ & 0.451 \\
\hline Other immunocompromising conditions and/or medications ${ }^{2}$ & 1.25 & $(1.20-1.30)$ & $<0.001$ & 1.26 & $(1.23-1.28)$ & $<0.001$ \\
\hline Cancer patient & 2.35 & $(2.29-2.42)$ & $<0.001$ & 1.18 & $(1.15-1.21)$ & $<0.001$ \\
\hline Receipt of autologous stem cell transplant & 2.07 & $(1.49-2.89)$ & $<0.001$ & N/A & & \\
\hline Receipt of allogeneic stem cell transplant & 1.92 & $(1.09-3.38)$ & 0.024 & & & \\
\hline Receipt of radiotherapy & N/A & & & 0.94 & $(0.93-0.96)$ & $<0.001$ \\
\hline Stage $1 / \|$ at diagnosis & & & & 1.01 & $(0.99-1.03)$ & 0.269 \\
\hline Stage III/IV at diagnosis & & & & 1.20 & $(1.16-1.23)$ & $<0.001$ \\
\hline
\end{tabular}

somewhat counterintuitive result may reflect different approaches (e.g., more aggressive chemotherapies, inducing greater immune suppression) used to treat elderly cancer patients aged 75 to 85 for cancer and other illnesses compared with approaches used to treat elderly cancer patients 85 years and older. These different treatment approaches may lead to different $\mathrm{HZ}$ risks. Habel, et al. reports a similar decreased risk of $\mathrm{HZ}$ for cancer patients 80 years and older compared to those younger than 80 years, but only among patients with hematologic cancers [6].

There is a wide range of estimates of post-herpetic neuralgia incidence ranging from $<1 \%$ to $70 \%$ previously reported in the literature, with this study reporting proportions of patients with HZ-related pain $(41.0 \%$ and $47.7 \%$ for solid and hematologic cancer patients, respectively) on the higher end [21-23]. This higher estimate may be a result of a possible lack of specificity of the claims data definition employed on the cancer population. Cancer patients may have other painful conditions associated with their oncological therapy that may be getting attributed to HZ-related pain.

This study has several notable limitations. As with all claims database analyses, ICD-9 codes were used to identify diagnoses; these codes may not reflect confirmed clinical diagnoses and lack information to assess severity of illness. Medical services obtained outside of a patient's plan are not captured in claims data, so $\mathrm{HZ}$ incidence in this study may be underestimated. The analysis of $\mathrm{HZ}$-related pain may not reflect the true incidence of HZ-related pain in the studied populations. Specifically, the definition may cause our study to overstate the incidence of HZ-related pain among cancer patients compared with non-cancer patients by classifying general cancer-related pain as HZ-related pain, particularly since pain may be more likely to be diagnosed in cancer patients (who likely receive regular evaluations and treatment) compared with non-cancer patients. No validation of codes and algorithms for identifying $\mathrm{HZ}$ and its complications was performed. However, a study that performed validation with comparison to electronic medical records found high positive predictive value (PPV) for identifying $\mathrm{HZ}$ and its complications (78\%93\%) [12]. The SEER-Medicare data extract used in this study did not include patients with multiple myeloma. Receipt of chemotherapy was not analyzed as an $\mathrm{HZ}$ risk factor due to the lack of available pharmacy claims data prior to 2007. Finally, some of the steroids defined as immunosuppressive treatments could be part of a cancer treatment protocol. 
Table 4 Incidence of $\mathrm{HZ}$ complications in hematologic and solid cancer patients

\begin{tabular}{|c|c|c|c|c|c|c|c|c|}
\hline \multirow[t]{2}{*}{ Outcome measure } & \multicolumn{4}{|c|}{ Hematologic cancer patients $(n=7,574)$} & \multicolumn{4}{|c|}{ Solid cancer patients $(n=58,670)$} \\
\hline & $\begin{array}{l}\text { First } \\
\text { events }\end{array}$ & $\begin{array}{l}\text { Person-years } \\
\text { of observation }\end{array}$ & $\begin{array}{l}\% \text { with } \\
\text { event }\end{array}$ & $\begin{array}{l}\text { Incidence rate per } \\
1000 \text { person-years } \\
(95 \% \mathrm{Cl})^{1,2}\end{array}$ & $\begin{array}{l}\text { First } \\
\text { events }\end{array}$ & $\begin{array}{l}\text { Person-years } \\
\text { of observation }\end{array}$ & $\begin{array}{l}\text { \% with } \\
\text { event }\end{array}$ & $\begin{array}{l}\text { Incidence rate per } \\
1000 \text { person-years } \\
(95 \% \mathrm{Cl})^{1,2}\end{array}$ \\
\hline Any Complication ${ }^{3,4}$ & 1,348 & 1,421 & 17.8 & $530.0(493.5-569.3)$ & 9,253 & 11,483 & 15.8 & $398.3(386.9-410.0)$ \\
\hline Cutaneous Complications & 291 & 1,652 & 3.8 & $122.8(107.1-141.0)$ & 1,462 & 13,296 & 2.5 & $73.6(69.1-78.3)$ \\
\hline Cellulitis & 289 & 1,653 & 3.8 & $122.2(106.5-140.3)$ & 1,456 & 13,297 & 2.5 & $73.2(68.7-77.9)$ \\
\hline Zoster gangrenosum & $<11$ & 1,776 & $<0.2$ & $0.6(0.1-4.0)$ & $<11$ & 13,973 & $<0.1$ & $0.4(0.1-0.9)$ \\
\hline Visceral Complications & $<11$ & 1,775 & $<0.2$ & $3.4(1.5-7.5)$ & $<11$ & 13,974 & $<0.1$ & $0.2(0.1-0.7)$ \\
\hline Pneumonitis & $<11$ & 1,775 & $<0.2$ & $3.4(1.5-7.5)$ & $<11$ & 13,974 & $<0.1$ & $0.2(0.1-0.7)$ \\
\hline Neurological Complications & 339 & 1,716 & 4.5 & $174.8(156.1-195.7)$ & 1,860 & 13,633 & 3.2 & $121.7(116.0-127.7)$ \\
\hline Aseptic meningitis & $<11$ & 1,775 & $<0.2$ & $4.5(2.3-9.0)$ & 30 & 13,969 & 0.1 & $1.5(1.0-2.3)$ \\
\hline Cranial nerve palsies & 42 & 1,766 & 0.6 & $18.1(12.8-25.6)$ & 223 & 13,918 & 0.4 & $11.9(10.2-13.8)$ \\
\hline Deafness & $<11$ & 1,777 & $<0.2$ & $0.0(0.0-0.0)$ & $<11$ & 13,974 & $<0.1$ & $0.1(0.0-0.6)$ \\
\hline Diaphragmatic paralysis & $<11$ & 1,776 & $<0.2$ & $2.8(1.2-6.8)$ & 52 & 13,964 & 0.1 & $3.2(2.3-4.2)$ \\
\hline Encephalitis & 26 & 1,772 & 0.3 & $13.0(8.6-19.5)$ & 106 & 13,953 & 0.2 & $6.5(5.3-8.0)$ \\
\hline Motor neuropathy & $<11$ & 1,776 & $<0.2$ & $0.6(0.1-4.0)$ & 17 & 13,971 & 0.0 & $1.2(0.8-2.0)$ \\
\hline Postherpetic polyneuropathy and postherpetic trigeminal neuralgia & 252 & 1,735 & 3.3 & $132.5(116.5-150.8)$ & 1,393 & 13,739 & 2.4 & $93.7(88.8-99.0)$ \\
\hline Sensory loss & $<11$ & 1,775 & $<0.2$ & $4.5(2.3-9.0)$ & 66 & 13,959 & 0.1 & $4.7(3.7-6.0)$ \\
\hline Transverse myelitis & $<11$ & 1,776 & $<0.2$ & $1.1(0.3-4.5)$ & 16 & 13,972 & 0.0 & $1.1(0.7-1.9)$ \\
\hline Other complications & $<11$ & 1,777 & $<0.2$ & $0.0(0.0-0.0)$ & $<11$ & 13,975 & $<0.1$ & $0.0(0.0-0.0)$ \\
\hline Ophthalmic Complications & 853 & 1,565 & 11.3 & $247.3(223.8-273.2)$ & 6,689 & 12,276 & 11.4 & $218.5(210.4-226.9)$ \\
\hline Dermatitis of eyelid & 337 & 1,700 & 4.4 & 94.1 (80.6-109.9) & 2,626 & 13,363 & 4.5 & $79.8(75.1-84.7)$ \\
\hline Iridocyclitis/Uveitis/Chorioretinitis/Retinitis & 84 & 1,759 & 1.1 & $31.3(24.0-40.7)$ & 624 & 13,836 & 1.1 & $31.2(28.4-34.3)$ \\
\hline Keratoconjunctivitis & 289 & 1,711 & 3.8 & 75.4 (63.4-89.6) & 2,058 & 13,499 & 3.5 & $60.3(56.3-64.6)$ \\
\hline Keratitis & 95 & 1,752 & 1.3 & $49.1(39.7-60.6)$ & 641 & 13,786 & 1.1 & $39.0(35.8-42.4)$ \\
\hline Mydriasis & $<11$ & 1,777 & $<0.2$ & $0.6(0.1-4.0)$ & $<11$ & 13,975 & $<0.1$ & $0.1(0.0-0.5)$ \\
\hline Panopthalmitis & $<11$ & 1,777 & $<0.2$ & $0.0(0.0-0.0)$ & $<11$ & 13,975 & $<0.1$ & $0.0(0.0-0.0)$ \\
\hline Ptosis & 16 & 1,771 & 0.2 & $9.0(5.5-14.7)$ & 184 & 13,928 & 0.3 & $12.3(10.6-14.3)$ \\
\hline Scleritis & 111 & 1,735 & 1.5 & $54.2(44.3-66.3)$ & 758 & 13,632 & 1.3 & $43.4(40.1-47.1)$ \\
\hline Visual impairment & 33 & 1,768 & 0.4 & $15.8(10.9-22.9)$ & 204 & 13,915 & 0.3 & $12.2(10.5-14.2)$ \\
\hline Other complications & 209 & 1,731 & 2.8 & $56.6(46.4-69.0)$ & 1,687 & 13,592 & 2.9 & $47.3(43.8-51.1)$ \\
\hline
\end{tabular}

Notes:
1 rates are estimated by Poisson regression with a log link. Patients with complications diagnosed on the same day as $\mathrm{HZ}$ are excluded from the regression due to lack of follow-up time. Thus, dividing the number of first events by the person-years of observation will not match the incidence rate estimates.

${ }^{2} \mathrm{Cl}=$ confidence interval.
${ }^{2} \mathrm{P}$.

${ }^{2} \mathrm{Cl}=$ confidence interval.
${ }^{3}$ The $\mathrm{p}$-value of the difference in $\%$ with any complication for hematologic vs. solid cancer was $<0.01$.

${ }^{4}$ See Additional file 1: Table S2 for ICD-9 codes used to define complications. 
Table 5 Incidence of herpes zoster-related pain

\begin{tabular}{llll}
\hline Outcome Measure & First events & Population & \% with herpes zoster-related pain \\
\hline All Cancer & $\mathbf{2 7 , 6 6 4}$ & $\mathbf{6 6 , 2 2 2}$ & $\mathbf{4 1 . 8}$ \\
Hematologic Cancers $^{2}$ & $\mathbf{3 , 6 1 1}$ & $\mathbf{7 , 5 7 4}$ & $\mathbf{4 7 . 7}$ \\
$\quad$ Chronic Lymphocytic Leukemia & 914 & 1,754 & 52.1 \\
Acute Lymphocytic or Acute Myeloid Leukemia & 79 & 257 & 30.7 \\
Other Leukemia & 161 & 391 & 41.2 \\
Hodgkin's Lymphoma $_{\text {Non-Hodgkin's Lymphoma }}$ & 133 & $\mathbf{2 8 3}$ & 47.0 \\
Solid Cancers & & 47.5 \\
Bladder Cancer & 2,324 & $\mathbf{4 , 8 9 1}$ & $\mathbf{4 1 . 0}$ \\
Breast Cancer & $\mathbf{2 4 , 0 7 0}$ & $\mathbf{5 8 , 6 7 0}$ & 41.4 \\
Colorectal Cancer & 1,716 & 43.1 \\
Head and Neck Cancer & 6,822 & 15,819 & 40.9 \\
Lung Cancer & 3,010 & 7,354 & 40.7 \\
Melanoma & 1,030 & 2,530 & 39.1 \\
Ovarian Cancer & 2,495 & 6,376 & 42.1 \\
Prostate Cancer & 1,666 & 3,961 & 40.6 \\
Soft Tissue Sarcoma & 343 & 844 & 39.4 \\
\hline
\end{tabular}

Notes:

${ }^{1}$ Patients were observed following the incident diagnosis of herpes zoster.

${ }^{2}$ P-values of differences in $\%$ of patients with herpes zoster-related pain for hematologic vs. solid cancer $<0.01$.

\section{Conclusions}

The results of this study indicate that elderly cancer patients face an increased risk of HZ compared to noncancer patients. Elderly patients with hematologic cancers are particularly vulnerable to $\mathrm{HZ}$ and related complications and pain. Gender, race, and certain immunocompromising conditions and certain cancer therapies are risk factors for HZ. Further research on $\mathrm{HZ}$ in cancer patients is needed within the context of non-Medicare populations as well as patients with multiple myeloma.

\section{Ethics statement}

The New England Institutional Review Board approved this retrospective analysis of Surveillance Epidemiology and End Results Medicare data for Medicare beneficiaries. This research was determined to be exempt from NEIRB review as it involved study of existing data. Informed consent was waived since the study does not involve intervention or interactions with individuals, only registry and claims data are used. The SEER-Medicare contact at the National Cancer Institute reviewed the manuscript and verified that there are no confidentially issues with the presented data.

\section{Additional file}

Additional file 1: Table S1. Codes to Identify Pain and Pain Interventions. Table S2. ICD-9 Codes to Identify HZ Complications. Table S3. Additional Variable Descriptions.

\section{Abbreviations}

HZ: herpes zoster; VZV: Varicella Zoster Virus; SEER: Surveillance, Epidemiology, and End Results; IR: Incidence rate; PY: Person-years;

$\mathrm{Cl}$ : Confidence intervals; IRR: Incidence rate ratios.

\section{Competing interests}

Research support was provided to Analysis Group, Inc. by GlaxoSmithKline Biologicals SA, Belgium. M. Yenikomshian, P. Karner, A. Trahey, and M. Duh were employees of Analysis Group, Inc. at the time the study was conducted A. Guignard and F. Haguinet are employees of the GlaxoSmithKline group of companies, A. Guignard receives stock equity as part of her compensation. A. Skarin and A. LaCasce are employees of the Dana-Farber Cancer Institute and have received consultation fees from GlaxoSmithKline Vaccines for this study.

\section{Authors' contributions}

AG conceived of the study. APG and FH designed the study. MAY, AT, PK, and MSD coordinated the study, prepared the data, and performed the statistical analysis. AL and AS provided clinical input on the study design and interpretation of results. All authors interpreted the findings. MAY and PK wrote the manuscript drafts. All authors critically reviewed different manuscript drafts and read and approved the manuscript.

\section{Acknowledgements}

Publication management and editorial support was provided by Jarno Jansen (Keyrus biopharma on behalf of GlaxoSmithKline Vaccines). This study used the linked SEER-Medicare database. The interpretation and reporting of these data are the sole responsibility of the authors. The authors acknowledge the efforts of the Applied Research Program, NCl; the Office of Research, Development and Information, CMS; Information Management Services (IMS), Inc.; and the Surveillance, Epidemiology, and End Results (SEER) Program tumor registries in the creation of the SEER-Medicare database.

\section{Author details}

${ }^{1}$ Analysis Group, Inc., 111 Huntington Ave., Tenth Floor, Boston, MA 02199, USA. ${ }^{2}$ GlaxoSmithKline Vaccines, Wavre, Belgium. ${ }^{3}$ Dana-Farber Cancer Institute, Boston, MA, USA. 
Received: 20 May 2014 Accepted: 6 February 2015

\section{Published online: 27 February 2015}

\section{References}

1. Arvin AM, Gershon A. Varicella-Zoster Virus - Virology and Clinical Management. 1st ed. UK: Cambridge University Press; 2000.

2. Harpaz R, Ortega-Sanchez IR, Seward JF. Advisory Committee on Immunization Practices (ACIP) Centers for Disease Control and Prevention (CDC). Prevention of herpes zoster: recommendations of the Advisory Committee on Immunization Practices (ACIP). MMWR Recomm Rep. 2008;6:1-30.

3. Dworkin RH, Johnson RW, Breuer J, Gnann JW, Levin MJ, Backonja M, et al. Recommendations for the management of herpes zoster. Clin Infect Dis. 2007:44:S1-26.

4. Cohen J. Herpes Zoster. N Engl J Med. 2013;369:255-63.

5. Habel LA, Ray GT, Horberg M, Yawn B, Castillo A, Li Y, et al. The epidemiology of herpes zoster in patients with invasive cancer. J Clin Oncol. 2009;27:9562.

6. Habel LA, Ray GT, Silverberg MJ, Horberg MA, Yawn BP, Castillo AL, et al. The epidemiology of herpes zoster in patients with newly diagnosed cancer. Cancer Epidemiol Biomarkers Prev. 2013;22:82-90.

7. National Cancer Institute (NCl): SEER. [http://seer.cancer.gov/about/overview. html] Accessed Nov. 7, 2013.

8. NCl: SEER-Medicare: How the SEER \& Medicare Data are Linked. [http:// healthservices.cancer.gov/seermedicare/overview/linked.html] Accessed Nov. 7, 2013

9. Insinga RP, Itzler RF, Pellissier JM, Saddier P, Nikas AA. The incidence of herpes zoster in a United States administrative database. J Gen Intern Med. 2005;20(8):748-53.

10. Volpi A. Severe complications of herpes zoster. Herpes. 2007;14:35-9.

11. Weaver BA. The burden of herpes zoster and postherpetic neuralgia in the United States. J Am Osteopath Assoc. 2007;107:S2-7.

12. Klompas M, Kulldorff M, Vilk Y, Bialek SR, Harpaz R. Herpes Zoster and Postherpetic Neuralgia Surveillance using structured electronic data. Mayo Clin Proc. 2011;86:1146-53.

13. Charlson ME, Pompei P, Ales KL, MacKenzie CR. A new method of classifying prognostic comorbidity in longitudinal studies: development and validation. J Chronic Dis. 1987;40(5):373-83.

14. Deyo RA, Cherkin DC, Ciol MA. Adapting a clinical comorbidity index for use with ICD-9-CM administrative databases. J Clin Epidemiol. 1992;45:613-9.

15. Romano PS, Roos LL, Jollis JG. Adapting a clinical comorbidity index for use with ICD-9-CM administrative data: differing perspectives. J Clin Epidemiol. 1993:46(10):1075-9

16. Rusthoven JJ, Ahlgren P, Elhakim T, Pinfold P, Reid J, Stewart L, et al. Varicella-zoster infection in adult cancer patients: a population study. Arch Intern Med. 1988;148:1561-6.

17. Yawn BP, Wollan P, St. Sauver J. Comparing shingles incidence and complication rates from medical record review and administrative database estimates: How close are they? Am J Epidemiol. 2011;174:1054-61.

18. Opstelten W, Van Essen GA, Schellevis F, Verheij TJ, Moons K. Gender as an independent risk factor for herpes zoster: a population-based prospective. Ann Epidemiol. 2006;16:692-5.

19. Schmader K, George LK, Burchett BM, Pieper CF. Racial differences in the occurrence of herpes zoster. J Infect Dis. 1995;171:701-4.

20. Schmader K, George LK, Burchett BM, Hamilton JD, Pieper CF. Race and stress in the incidence of herpes zoster in older adults. J Am Geriatr Soc. 1998;46:973-7

21. Gnann Jr JW, Whitley RJ. Clinical practice. Herpes zoster. N Engl J Med. 2002;347:340-6.

22. Opstelten W, Mauritz JW, de Wit NJ, van Wijck AJ, Stalman WA, van Essen GA. Herpes zoster and postherpetic neuralgia: incidence and risk indicators using a general practice research database. Fam Pract. 2002;19:471-5.

23. Yawn BP, Saddier P, Wollan PC, St Sauver JL, Kurland MJ, Sy LS. A population-based study of the incidence and complication rates of herpes zoster before zoster vaccine introduction. Mayo Clin Proc. 2007:82:1341-9.

\section{Submit your next manuscript to BioMed Central and take full advantage of:}

- Convenient online submission

- Thorough peer review

- No space constraints or color figure charges

- Immediate publication on acceptance

- Inclusion in PubMed, CAS, Scopus and Google Scholar

- Research which is freely available for redistribution 